\title{
A literatura infantil e juvenil em foco - o ensino, a pesquisa e a publicação ${ }^{1}$ Children's and young people's literature in focus - the teaching, research and publication
}

Vânia Maria Resende

Sem vínculos institucionais regulares, professora convidada para trabalhos com Universidades

\section{Resumo}

O ensino e a pesquisa podem ter função auxiliar no amadurecimento da consciência subjetiva e objetiva, nos modos de pensar sobre si mesmo e sobre a realidade, com possibilidades de processarem mudanças concretas no mundo interno e externo, na evolução incessante do pensamento e da sociedade. A afirmação presume que aspectos teóricos e metodológicos são pressupostos importantes, subsidiários ao desenvolvimento da recepção crítica dos leitores e de práticas leitoras que se consolidam, amplificam e renovam a cada novo ato de leitura; por cada leitor; em cada época e lugar específicos. Decorre, ainda, deste aspecto o questionamento de que os modos de recepção da leitura estão sujeitos aos modos de produção que se atualizam e modificam historicamente.

A dimensão expansível da consciência dos leitores de todas as idades principalmente de crianças e jovens, não leitores independentes ainda, em estágios de iniciação e formação de atitudes, preferências, competências, - encontra respaldo significativo na literatura de um modo geral, e particularmente na literatura infantil e juvenil, cujo campo de alcance da presente abordagem, o nacional, abrange da configuração estética do gênero, na década de 20, com Monteiro Lobato, à vasta produção editorial contemporânea.

Palavras-chave: leitura, literatura, leitores, produção, recepção, crítica, pesquisa, ensino.

\section{Abstract}

Teaching and research may have an auxiliary function in the maturing of the subjective and objective conscience, on the ways of thinking about oneself and about reality, with the possibility of processing concrete changes in the inner and outside world, in the ceaseless development of thought and society. This assertion presumes that theoretical and methodological aspects are important conjectures, subsidiary to the

\footnotetext{
${ }^{1}$ Este artigo amplia o texto-base norteador da mesa-redonda com o mesmo título, do dia 15/6/ 2007, no I SELL/ UFTM.
} 
development of the critical receptivity in readers, and of the reading practices that are consolidated, amplified and renewed in each new reading act; by every reader; in each period and specific place. From this aspect there arises the issue concerning the fact that the forms of reading reception are subject to the forms of production which are renewed and modified historically.

The expansible dimension of conscience in readers of all ages - mainly children and young people, who are not yet independent readers, in the stages of initiation and development of attitudes, preferences, competences - finds enough support in literature as a whole, and mainly in children's and young people's literature. This article, in a national scope, encompasses from the esthetic configuration of the genre in the twenties with Monteiro Lobato to the vast production of current publishers.

Key words: Reading, literature, readers, production, reception, criticism, research, teaching.

\section{Introdução}

O tema em questão, que põe a literatura infantil e juvenil em pauta, se desdobra em vertentes complexas. Os três aspectos - ensino, pesquisa e publicação - dão margem a reflexões específicas; o aprofundamento que inter-relacione estes aspectos ou a ênfase específica sobre cada um deles suscita o levantamento de questões várias, que envolvem uma rede de agentes: educadores, pesquisadores, bibliotecários, editores, gráficos, artistas gráficos, ilustradores, escritores, entre outros. Áreas científicas também se associam ao campo em foco, já que ele pode ser tratado sob o ponto de vista de múltiplos vieses analíticos, implicando relações com áreas do conhecimento proximais: de Estudos da Linguagem, Leitura, Lingüística, Teoria da Literatura, História da literatura, Estética, Semiótica, Crítica literária, ou, ainda, com várias outras: Psicologia, Pedagogia, Sociologia, Biblioteconomia, Artes Gráficas, llustração, Desenho, Editoração, etc.

Aprofundando-nos em um dos aspectos do tema - "publicação" - nos concentraremos no objeto livro, tal como o conhecemos e manejamos na sociedade ocidental. Como produto industrial, que resulta em suporte reproduzido em série, deixa para trás o modelo monástico, modificando os rumos da leitura, ampliando o público leitor e a abertura das possibilidades de recepção e interpretação. Poremos em foco o livro para crianças, com a peculiaridade das multilinguagens, que o compõem e o distinguem pela pluralidade de camadas sígnicas, que se desdobram em sentidos, processados não na relação exclusiva com o texto verbal, mas na complementaridade de planos: verbais, imagísticos, gráficos, espaciais. Evidenciaremos a produção editorial para crianças e 
jovens no Brasil, vendo a evolução do gênero "livro infantil", mapeando a história que registra saltos formidáveis de qualidade em termos experimentais, inovadores.

\section{A leitura na escola}

A percepção crítica da mente autônoma e criadora se aprofunda e ganha versatilidade e abrangência à medida que o leitor absorve, compara, associa, opina, penetra a relatividade das significações, em decorrência do contato com uma gama diversificada de linguagens e leituras, tanto da vertente da cultura artística e literária, como da informativa, técnica, científica. Quantas vezes temos falado e ouvido falar sobre a desejada autonomia dos sujeitos e dos grupos, acreditando que a leitura possa funcionar favoravelmente na consolidação do pensamento analítico, e que este representa poderes ao indivíduo e à sociedade no sentido da humanização dos seus potenciais, da condição de cidadania, da convivência harmoniosa de cada um consigo mesmo e com o seu entorno!

A consciência humanizada, politizada, antenada com o tempo presente, com a memória do passado e com sonhos do futuro se constrói, não se manifesta como obra do acaso ou gratuitamente. Ela se forma em movimento contínuo e cumulativo, em que as leituras fornecem horizontes múltiplos, variados, abertos pelo pensamento novo, que discorda de verdades absolutas e lineares, percorre o mundo por vieses plurais, variados, concebendo-o à luz de reformulações e de uma saudável instabilidade. Transitar pela realidade e agir nela com esta compreensão depende do arsenal de leituras, de conhecimentos bem assimilados; se a escola educa em virtude de fundamentá-la, o nível de curiosidade diferenciado faz o ser humano exceder as informações do domínio didático, para volver-se ao incomensurável da vida e do conhecimento na busca infindável. Através da leitura do que é útil e do que é belo, o indivíduo supre desejos e desenvolve necessidades utópicas, vislumbrando, equilibradamente, universos de dimensões ora mais objetivas, razoáveis, ora de instigante virtualidade criadora, onde a subjetividade mergulha e emerge revigorada, plena de sonhos, mas lúcida. $A$ formação pedagógica em que o sentido da linguagem é de instituir interligações perspicazes e surpreendentes com a vida, a cultura, a História embasa a conquista de liberdade para os sujeitos e as comunidades humanas, com o pensamento independente e criativo; assim é que vemos realizadas práticas leitoras comprometidas com o desenvolvimento humanosocial, libertador, estético e sistêmico, versus idéias imutáveis, padrões fixos, relações submissas e opressoras, visão ingênua e fragmentária.

Quanto ao livro para crianças e jovens, que se caracteriza por relações intersemióticas peculiares no seu modo de produção, o alcance da interação entre leitor-obra 
estende-se do simples divertimento à leitura de natureza crítica, analítica (que não exclui necessariamente o sentido lúdico), admitindo-se, ainda, limitantes cumprimentos de rituais pedagógicos, de que resultam leituras sofridas e enfadonhas dentro da escola. Convenhamos que há níveis e níveis de obras; algumas abrigam elevado grau de criatividade e de novidade, outras são desfalcadas, totalmente precárias. Consideremos quanto à recepção que certas práticas de leitura mediadas pela escola não alcançam o valor de obras literárias ricas, atendendo cumprimentos formais, inadequados, sem vigor.

O modo raso de levar a ver/ler, desinteressado da complexidade, fica à procura do elementar, superficial, confinado ao empobrecimento de metodologias e avaliações padronizadas e padronizadoras. Nesse modo, ler se confunde com obrigação, ficando reduzido a responder fichas de leitura (tem editoras que encaixam no livro literário, pedagogicamente rotulado de paradidático, a do aluno e a do professor, esta com respostas prontas); fazer resumos maçantes; preencher questionários e/ ou linhas pontilhadas; explorar vocabulário, etc. Quando a literatura se torna saber escolar administrado segundo contenções, ordens, confinamentos impostos pela organização didática, e o aluno é levado a ler não para si, mas para o professor, para a prova, a leitura fica subjugada à escolarização perniciosa. Vale ponderar que

o que se deve negar não é a escolarização da literatura, mas a inadequada, a errônea, a imprópria escolarização da literatura, que se traduz em sua deturpação, falsificação, distorção, como resultado de uma pedagogização ou uma didatização mal compreendidas que, ao transformar o literário em escolar, desfigura-o, desvirtua-o, falseia-o. (SOARES, 1999, p. 22).

\section{Novos modos de produção, novos modos de leitura}

Através dos tempos, novos recursos são assimilados, compondo-se, assim, novos suportes e meios expressionais. Assistimos, nos tempos modernos, a revoluções tecnológicas, com adesão à simultaneidade da comunicação, onde signos acoplados em diálogo realizam o verdadeiro hibridismo de linguagens. Da escrita à mão em diversos materiais (pedra, madeira, pergaminho, pano...) aos tipos e máquinas, usados pela imprensa, na industrialização, à adoção de novos recursos digitais, a escrita passa por transformações, resultando em novos modos de produção e de recepção da linguagem, do texto, do livro. É compreensível que "a significação, ou melhor, as significações, histórica e socialmente diferenciadas de um texto, qualquer que ele seja, não podem separar-se das modalidades materiais que o dão a ler aos seus leitores." (CHARTIER, 1994, p. 105).

A produção editorial para crianças e jovens, que se tem tornado prodigiosa, no Brasil, em especial a partir da década de 70, vem acompanhada de crescentes 
questionamentos e estudos, constituindo-se em objeto de trabalhos científicos (monografias de conclusão de cursos de graduação e pesquisas em todos os níveis de pós-graduação), com vínculos produtivos com sistemas educativo-pedagógicos, sociais e culturais do país. A produção mencionada é fonte profícua aos pesquisadores, uma vez que o objeto da investigação (o livro infantil e a sua leitura) comporta especificidade na interface de códigos, interpostos na composição híbrida.

Se o ensino e a pesquisa, implementados na Universidade e nos níveis Fundamental e Médio, forem instituições conceptuais do pensamento complexo, por serem elas próprias, no cerne da sua estrutura e funcionamento, questionadoras, terão interferências sociais, adentrando conflitos e valores, não só ao refletir, constatar, relatar, mas também experimentar, criar e ousar, com formulações e ações inovadoras, responsáveis por reformas fora e dentro da escola. Na área da leitura literária, o eixo crítico pode detonar didatismos e noções unilaterais, métodos separatistas dos opostos, remexendo os meios e os fins. Empenhados em "repensar a reforma e reformar o pensamento", a pesquisa e o ensino revisarão, redirecionarão, reestruturarão paradigmas vigentes, revertendo, no caso de tendências conjunturais dominantes, a fragmentação da cabeça compartimentada e o peso do pragmatismo. Para E. Morin, essa reforma aponta para a complementaridade da condição humana e das culturas científica e humanística:

À maneira de um ponto de holograma, trazemos, no âmago de nossa singularidade, não apenas toda a humanidade, toda a vida, mas também quase todo o cosmo, incluso seu mistério, que, sem dúvida, jaz no fundo da natureza humana.

Eis, pois, o que uma nova cultura científica pode oferecer à cultura humanística: a situação do ser humano no mundo, minúscula parte do todo, mas que contém a presença do todo nessa minúscula parte. Ela o revela, simultaneamente, em sua participação e em sua estranheza ao mundo. Assim, a iniciação às novas ciências torna-se, ao mesmo tempo, iniciação a nossa condição humana, por intermédio dessas ciências. (MORIN, 2001, p. 41).

\section{Literatura infantil brasileira: Monteiro Lobato no ponto de partida}

É capítulo importante na história da produção e edição do livro infantil brasileiro a atuação de Monteiro Lobato no campo literário e editorial. Quanto ao escritor, historicamente tem sido focada a sua condição de inaugurador de caminhos, por ter solidificado um projeto literário sério, inovador, em que componentes essenciais do universo fantástico se inter-relacionam na tessitura lúdica de idéias, comportamentos, espaços, linguagem. Amalgamado pela consciência estética madura do intelectual, já manifestada na literatura adulta, este novo projeto literário sustentou-se em princípios dinâmicos, vitais, criativos, propulsores da convivência natural do leitor infantil com facetas insólitas da imaginação, com a dimensão mágica de invenções e aventuras 
fabulosas. A visão crítico-criativa lobatiana foi fundadora de realidades imaginosas, não alienantes, muito pelo contrário, questionadoras, por fazerem pensar o mundo através do ponto de vista aberto, muldimensional, complexo, poético. Na obra A reforma da natureza, a desvendadeira Emília revira o modelo de realidade e os fundamentos da natureza, com idéias reformadoras de estruturas vigentes, questionando a ordem social e seus gestores, vistos como insatisfatórios e ridículos; no modelo ideal, Dona Benta representa a conduta democrática ideal, em contraste com ditadores famosos de outros continentes, como a Europa. As camadas fantásticas encobrem verdades e valores do mundo adulto, denunciando sutilmente e recriando a realidade normatizada.

Monteiro Lobato foi hábil ao expurgar ranços, pieguices, literatices da linguagem que atingiu a comunicação com as crianças via palavra artística, subversora do discurso infantilizado e infantilizador. Eleva-se até ao nível das peculiaridades do pensamento infantil, que é naturalmente transgressor da lógica conhecida; o pó de pirlimpimpim faz a passagem para o mundo das imprevisibilidades e dos absurdos: os habitantes do Sítio vão a quaisquer pontos do universo e de outras geografias e reinos imaginários e voltam ao seu familiar espaço rural. Aventuras ricas em surpresas, atitudes mirabolantes povoam Memórias da Emília, A chave do tamanho, Os doze trabalhos de Hércules, entre outras obras, que renovam, criam e recriam espaços mitológicos, fabulares, universos literários clássicos, absorvem componentes culturais e sociais brasileiros e universais.

As personagens do Sítio do Pica-pau Amarelo - adultos, crianças, a boneca, o Sabugosa e animais personificados - viajam pelos espaços da fábula, do mito, dos contos da tradição oral, da literatura universal; encontram, por exemplo, nas alturas, um anjinho de asa quebrada que é trazido para a terra. Aqui Emília Ihe ensina a falar corretamente a língua dos humanos. Lobato renova os extratos simbólicos, os atualiza criativamente, os duplica na intertextualidade. Tem valor cômico e poético a palavra no universo literário lobatiano. As atrapalhações do anjinho com a língua que está aprendendo, por exemplo, são providas desse valor; as dificuldades lingüísticas da personagem celestial veiculam a carga de ambigüidades que a língua comporta e expressam a singularidade da personagem ímpar do universo lobatiano, que é Emília.

Quem ficava atrapalhado era o anjinho. Emília tinha um modo desnorteado de pensar. Assim, por exemplo, as suas célebres "asneirinhas". Muitas vezes não eram asneiras - eram modos diferentes de encarar as coisas, como quando explicou ao anjinho o caso das frutas do pomar.

- "Frutas são bolas que as árvores penduram nos ramos, para regalo dos passarinhos e das gentes. Dentro há caldos ou massas de todos os gostos. As maçãs usam massas. As laranjas usam caldo. E as pimentas usam um ardor que queima a língua da gente."

"- Então têm fogo dentro? Fogo é que queima." 
Emília ria-se. (LOBATO, 2 a, 1973, p. 96).

O senso humorístico e poético (fator constituinte da concepção literária, independente de idade a que o texto se destine) explorado por Monteiro Lobato reverte a mesmice das idéias consensuais e previsíveis dentro da lógica racional; empregado, por ele, na literatura para crianças, afina-se ao ludismo, que é inerente à mente infantil e corresponde às necessidades e expectativas da infância. Lobato aliou à visão lúdica, fantástica, o propósito de extirpar enfeites, excessos, de que resultou a simplicidade, não o empobrecimento do texto. Em carta de 19/12/1945 a Godofredo Rangel (da correspondência que durou de 1903 1948, ano da morte do escritor), ele afirma que

Para ser infantil tem o livro de ser escrito como o CAPINHA VERMELHA, de Perrault. Estilo ultradireto, sem nem um granulo de "literatura" [...]

A coisa tem de ser narrativa a galope, sem nenhum enfeite literário. [...]

Não imaginas a minha luta para extirpar a literatura dos meus livros infantis. A cada revisão nova nas novas edições, mato, como quem mata pulgas, todas as "literaturas" que ainda as estragam. Assim fiz no Hércules, e na segunda edição deixa-lo-ei ainda menos literário do que está. Depois da primeira edição é que faço a caçada das pulgas - e quantas encontro, meu Deus! (LOBATO, 1972, p. 372).

Através da sua editora, registrada em 1919 com o nome Monteiro Lobato \& Cia., o intelectual de idéias e ação, empreedeu a publicação, tanto de obras de sua autoria, quanto de outros autores, contemporâneos seus, da literatura adulta. Para a história do livro no Brasil, não apenas referente a obras para crianças, ele ocupa espaço memorável justamente porque,

Quando o pequeno mundo editorial brasileiro ainda engatinhava, nossos livros eram impressos em Portugal e na França, por iniciativa das pioneiras Francisco Alves e Garnier. O horizonte, no início do século $[X X]$, não se mostrava muito favorável às empresas nacionais, que eram bem poucas, por causa das dificuldades naturais de importação de máquinas e, principalmente, por seu preço.

Se não tivesse havido um Monteiro Lobato, a história talvez fosse bem outra. Foi ele quem nos anos 20 viu longe: um país como o Brasil precisava de um parque gráfico à altura de suas necessidades. O autor de Urupês deu os primeiros passos para montá-lo, à mesma época, quando se endividou não só para adquirir as melhores máquinas disponíveis no exterior, como para contratar técnicos do calibre de Natal Daiuto, então chefe da gráfica da Imprensa Oficial do Estado e um dos profissionais mais respeitados do mercado. (MIRA, 1996, p. 56).

Na sua curta experiência editorial e gráfica, Monteiro Lobato foi responsável por fazer o livro literária e graficamente bem feito para criança, valorizando a qualidade do suporte. Para tanto, ele arregimentou ilustrador de valor, contou com máquinas importadas para atenderem o processamento gráfico mais exigente; empenhou cuidado em todo o processo, decorrente de um planejado projeto editorial, que destinou, para seu 
já qualificado texto, suporte de excelência também. Um dos resultados deste empenho é o livro com figuras, do próprio Lobato, de 1920, da Editora Monteiro Lobato \& Cia., intitulado A menina do Narizinho Arrebitado (ilustrações de Voltolino); a obra continha episódios reduzidos com relação à edição ampliada que, posteriormente (1931), recebeu o título Reinações de Narizinho (ilustrações de Belmonte).

No momento fundador da literatura infantil no Brasil com Monteiro Lobato, entre as décadas de 20 e 40, em que o escritor concebe e desenvolve o seu projeto literário alicerçado em finalidades e resultados estéticos, o cerne da definição do gênero é o substantivo, não a sua sujeição ao objetivo pedagógico, ostensivamente formativo; ele investiu na maior parte da sua produção infantil o espírito brincalhão e libertador. Não cabe neste breve espaço, nem é o nosso objetivo no momento, estudo particularizado do autor, distinguindo níveis, na sua criação, entre o mais literário e tendências à informação, infiltradas, em determinadas obras, nas camadas fabulares.

O autor, apreciado e reconhecido pela importância do legado do seu projeto de literatura para crianças, atingiu leitores além do território nacional. A título de curiosidade, o internacionalmente conhecido Alberto Manguel (autor de Uma história da leitura, Biblioteca à noite, entre outros), referencial na área de estudos de história da leitura, imagem, biblioteca, etc., diante desta pergunta "Que autores tiveram grande influência sobre o senhor?" (entrevista na revista Veja, 7 de julho de 1999), declarou:

Um nome que me ocorre é o do brasileiro Monteiro Lobato, autor do Sítio do Pica-Pau Amarelo. Ter lido Monteiro Lobato numa certa fase de minha vida foi mais enriquecedor do que ter lido Camões, há cinco anos. Camões é interessante, levoume a pensar em questões profundas, mas não mudou minha vida. Tive contato com as obras de Lobato aos 8 anos, logo depois de mudar para a Argentina. Eu relacionava alguns episódios protagonizados pela boneca Emília com certas dificuldades que tive na escola nova, por causa do idioma que eu não falava.

É indubitável o alcance que a obra de Monteiro Lobato teve e continua tendo como inauguradora da literatura para crianças e jovens no Brasil, o que se mede pela infiltração de uma das suas mais importantes personagens (Emília), e, com menos ênfase, de outras mais do Sítio do Pica-pau Amarelo no imaginário popular. Popularidade para a qual contribuíram também as adaptações da sua obra pela TV, ao longo dos anos. Outro importante parâmetro do interesse pela obra do autor é constatável na esfera intelectual, o que se mensura pelas pesquisas acadêmicas e publicações sobre ele (muitas dessas, originárias de trabalhos científicos desenvolvidos em programas de pós-graduação). Há estudos que atribuem a grandes escritores e ilustradores atuantes na contemporaneidade a condição de "filhos de Lobato", herdeiros da sua irreverência criadora, aplicada em 
"reinações renovadas", usando termo subseqüente ao título De Lobato a Bojunga (obra de Laura Sandroni, dissertação de mestrado editada pela Agir em 1987).

Como enfatizamos, a obra lobatiana tem sido analisada por variados prismas, em inúmeros estudos que circulam no espaço acadêmico e no mercado editorial. Seria oportuna, então, esta pergunta: é possível crianças e jovens serem leitores de Monteiro Lobato hoje? Qual é o perfil destes leitores do presente, de últimas décadas do século XX e primeira década do XXI? São fatores culturais, lingüísticos, psicológicos ou pedagógicos que determinam interferências na motivação e interesse, dificultando a interação com essa obra, produzida há mais de 60 anos?

Visitamos o site www.iel.unicamp, e confirmamos em 14/6/2007 alguns dados no Fundo Monteiro Lobato/ projeto temático "Monteiro Lobato (1882-1948) e outros modernismos brasileiros", coordenado por Marisa Lajolo. Apresentamos o registro bibliográfico sobre o autor, considerando que o resultado do levantamento é relevante, ainda mais que o número computado tem por base apenas uma fonte pesquisada:

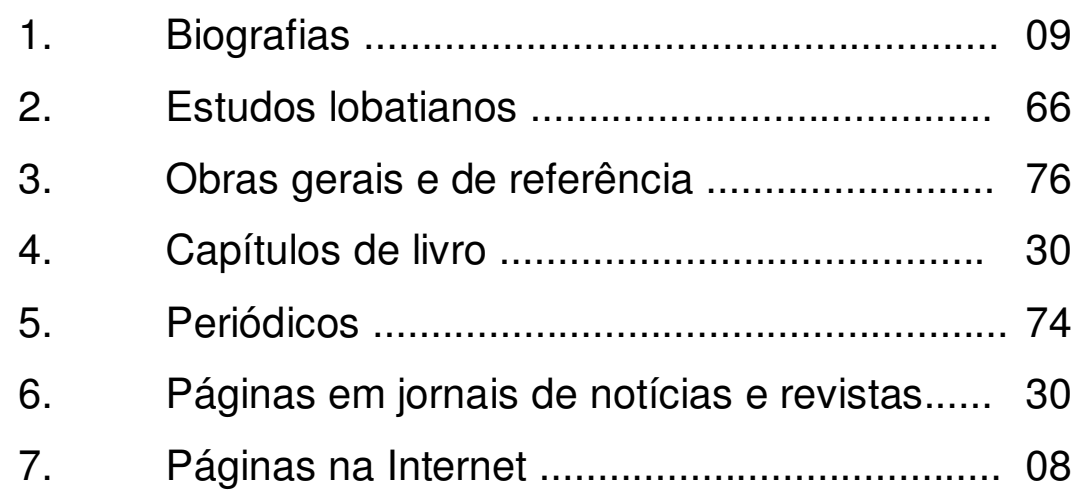

\section{Evolução e quantificação do livro para criança no Brasil}

A professora universitária Maria Zaira Turchi, no capítulo "Espaços da crítica da literatura infantil" faz alusão ao número expressivo de dissertações e teses sobre escritores e ilustradores de livros para crianças e jovens, emergentes no cenário brasileiro dos anos 70 em diante. A partir desta década, o gênero se expande em inovação e experimentalismo em termos nacionais, ganhando relevância a qualidade global do objeto livro infantil, onde se imprime concepção crítico-criativa e experimentalismo estético.

A pesquisadora reconhece que "qualidade estética é um passo decisivo na valorização do gênero infantil e juvenil e na fixação de seu estatuto como literatura" (TURCHI, 2006, p. 29). Complementando a sua afirmação, é legítimo considerar que "a crítica é [...] responsável por promover a valorização da literatura infantil e juvenil como instituição literária". A leitura interpretativa de finalidade crítico-analítica abalizada reconhece (às vezes descobre), explicita, fundamenta o valor da obra. É nele que reside a 
potencialidade das significações, de onde emana a força de atualidade, disponibilizada em inesgotáveis recepções, leituras, abordagens inéditas. Presume-se que as leituras críticas suscitam novos focos de pesquisa, novos pontos de vista, com base em diferentes métodos e teorias, em incontáveis desdobramentos analíticos. Em sondagem ao banco de dissertações e teses da CAPES, Maria Zaira constata que Monteiro Lobato é o mais estudado (mais de 100 trabalhos em áreas diferentes, e não só sobre literatura infantil). Da consulta ao sistema nacional de pós-graduação ela extrai resultado (a partir de 1987) não exaustivo, mas significativo (TURCHI, 2006, pp. 27-8):

\section{Autores}

\section{Total}

Ana Maria Machado: 26 dissertações/ 2 teses 28

Lygia Bojunga Nunes: 23 dissertações/ 5 teses 28

Ziraldo: 13 dissertações/ 6 teses 19

Marina Colasanti: 16 dissertações/ 2 teses 18

Ruth Rocha: 13 dissertações/ 1 tese 14

Sylvia Orthof: 8 dissertações 08

Angela Lago: 5 dissertações/ 1 tese 06

Roseana Murray: 3 dissertações 03

A literatura infantil brasileira, cuja produção se acelera a partir dos anos 70 , se reveste de maturidade da expressão lúdica e estética da linguagem, já preponderante no projeto de Monteiro Lobato. A partir destes anos a mentalidade criadora se consolida no corpo bem maior que o constituído pela obra de um só autor. Ao conjunto de escritores soma-se um elenco competente e criativo de ilustradores, artistas gráficos, editores. Delimitamos como marco significativo desse período a obra Flicts, de 1969, do artista (escritor, ilustrador, artista gráfico) Ziraldo. Flicts representa novos passos na história do livro para crianças e jovens, pela realização gráfico-literária renovadora que revoluciona os modos de produção e de leitura de livro/ literatura para crianças no país, modos que terão reflexos sobre edições modernizadas de textos da literatura adulta, como veremos posteriormente. A partir de um balanço da produção que abrange de Lobato aos autores que se alinham à obra de 69, concluímos que a ficção infantil lobatiana se estrutura essencialmente com o plano verbal, é dele que depende a narratividade; já a produção e recepção de obras como Flicts são semióticas, se dão pela ação inter-sígnica (RESENDE, 2004, pp. 19 e 60).

É notável, cada vez mais, o aparecimento de produções criativas em que o experimentalismo das facetas literária e gráfica do livro infantil se complementam e se 
enriquecem no diálogo artístico. A definição da literatura se rearticula, quando conjuga e torna inseparável, pelo hibridismo dos modos de produção, texto verbal/ suporte material (com tudo que se imprime nele). Na ação multidimensional das pluri-formas em interatividade, os sentidos provêm da relação das partes em função do todo, percebidos em gestalt. $\mathrm{Na}$ interdependência de aspectos formais e semânticos têm propriedade conotativa, não sendo secundários ou dispensáveis à interpretação, elementos como: cores, textura do papel, formato do livro, tamanho e tipo de letra, espaçamentos nas páginas, espaços vazios, vazados, local ocupado pelo texto e pelas imagens no espaço, disposição e divisão do texto, etc. Determinam ritmos, pausas, criam ambiências, sugerem estados emocionais, auxiliam na caracterização física e psicológica de personagens. Cortes, diminuição ou aumento do corpo das letras, a forma gráfica do texto têm, às vezes, função icônica, indicial ou simbólica importante; detalhes aparentemente irrelevantes podem ter efeitos determinantes no plano sintagmático e de significações paradigmáticas.

Interessantes projetos editoriais de reedição de obras clássicas e modernas renovam os modos da escrita - de poemas e textos em prosa - casada ao novo suporte. Servem de exemplo, entre outros que se misturam ou se integram ao corpus da literatura para crianças e jovens: "Ismália", de Alphonsus de Guimaraens, com ilustrações e projeto gráfico de Odilon Moraes, da editora Cosac e Naify, 2006; "Canção da tarde no campo", de Cecília Meireles, da editora Global, 2001. Este, transformado em livro, não só se harmoniza com uma linguagem plástica suave, de Ana Raquel, o que, por si, já lhe imprime abertura para novos olhares e significados interativos, como se desdobra em vários pequenos segmentos estróficos, que rearranjam o corpo do texto em pequenos poemas; assim, pode ser lido todo o poema na seqüência das páginas, ou sob a forma segmentada de mini-poemas. As divisões e montagens textuais, decorrentes do suporte atual, inauguram inusitados direcionamentos do olhar e da perspectiva interpretativa.

Provém de editoras como Global, Cosac e Naify, Nova Fronteira, entre outras, trabalhos valiosos não só com poemas, mas também com contos e crônicas. $O$ conto de Guimarães Rosa, Fita verde no cabelo (Nova Velha estória), por exemplo, originalmente publicado na obra póstuma Ave palavra (1970, Livraria José Olympio), reeditado (em 1992 pela Nova Fronteira) se enriquece, na condição de livro, com as nuanças da interface do texto com projeto gráfico e ilustrações do artista Roger Mello. Outro exemplo de texto ficcional curto transformado em livro é a crônica "História triste de tuim", de Rubem Braga; transportada da obra adulta Ai de ti, Copacabana (a 1ª edição é de 1960), para a reedição independente em livro, sob o título $O$ menino e o tuim, de 1986, da 
Quinteto Editorial, ilustrado por Denise Frailfeld e Fernando José A. Azevedo, ganha estatuto de literatura infantil (conforme identificação de gênero na ficha catalográfica).

Além das considerações mais generalizantes quanto à recepção de textos literários reeditados, existem níveis de maturidade lingüística e psicológica variáveis entre os sujeitos, ainda que identificados por alguns traços comuns. Ao aventarmos as vantagens das reedições bem feitas, com esmero gráfico-artístico, não estamos afirmando que toda nova edição (não adaptações, de clássicos, por exemplo) torna o texto acessível a leitor de todas as idades. É importante se levar em conta que a nova cara que um texto ganha não pode ser admitida como procedimento elementar, aparente, sem conseqüências formais, porque os novos dispositivos gráficos reviram estruturalmente as formas anteriores; quanto à história do livro para criança e jovem no Brasil, formas atualizadas podem estar contribuindo para dissolver distâncias e barreiras entre a literatura para 0 público adulto e a literatura para o público infantil e juvenil. O que a nova formatação de obras reeditadas acarreta à leitura é uma questão complexa, pela variedade de hipóteses possíveis a suscitar pesquisas na área da recepção, e pela riqueza do material (obras literárias clássicas e modernas), sendo cada reedição (ou mais de uma do mesmo texto) um caso específico, sujeito à análise crítica que melhor se aplique a ela.

É de Ziraldo - inaugurador, com Flicts, de uma condição multi-sígnica do texto, em que componentes visuais e espaciais não se comportam absolutamente como mera "ilustração" (como enfeite justaposto à palavra) - um novo modo de concepção e feitura do livro para crianças no Brasil, em que se processa a junção de códigos. Esta ação semiótica - dinâmica, simultaneísta, conjugada - dos signos, dos códigos, das artes confere à obra e à leitura reservas multiplicadas, implícitas à virtualidade plurisignificativa. A concepção de livro infantil do artista (entrevista ao Jornal do Professor de $1^{\circ}$ grau, março, 1987) retrata a importância da materialidade, onde o leitor se movimenta concretamente no ato da leitura; Ziraldo nos incita a pensar que o livro fechado é como casa desabitada; no livro-casa a literatura se inscreve, transformando-se em possibilidades vivas de sentido, quando o leitor, de tempo e espaço reais, o habita:

O livro é um objeto perfeito. É o objeto mais perfeito que o homem criou. [...] é um superdesenho. Você abre, você move a página, é o tempo; você pára, é o espaço. A vida está dentro do livro - contida nele -, você está com a vida nas mãos.

A obra de Ziraldo é um exemplo de ação intersemiótica na construção do conjunto livro/literatura. Ele reúne, pelo seu histórico de criador de histórias em quadrinho, artista gráfico, desenhista, escritor, jornalista, chargista, competências para uma autoria solo. 
Muitas vezes, a autoria de uma obra soma trabalho artístico e profissional de várias pessoas. Outros artistas, como Ziraldo, realizam também a feitura do livro infantil como uma orquestração artística, regida por mãos talentosas, como as de Ângela Lago, Ricardo Azevedo, Roger Mello, Eva Furnari, Marilda Castanha, e outros. A composição intertextual que engendram permite colagens, interposições, montagens, recortes, aproveitamento do já pronto, processos intertextuais, de citações, estilizações, paródias, etc., traz modificações irreverentes de estrutura e linguagem, que desestabilizam os limites entre gêneros literários, cuja natureza, na reconstrução experimental, deixa de ser fixa ou pura.

A literatura infantil e juvenil brasileira pós-70 dispõe de contingente expressivo de autores (escritores, ilustradores, artistas gráficos) e editores que investem na qualidade do objeto livro; cresce em surpresas e originalidade, alojando produções admiráveis, obras-primas, que somam o profissionalismo às vezes de uma equipe, responsável pelo trabalho artístico, gráfico e editorial. Os produtos editados têm repercussões favoráveis não só no cenário cultural, educacional, social e econômico nacional, mas também no âmbito de mercados e culturas internacionais. O interesse pelo livro feito no Brasil é notável em grandes feiras no exterior; versões para vários idiomas; prêmios importantes concedidos a escritores e ilustradores brasileiros.

\section{Publicação, pesquisa, ensino: intersecção e pontuações críticas}

A acelerada produção editorial brasileira para crianças e jovens encontrou na escola de nível fundamental a grande aliada para divulgação/ adoção de obras literárias. O lado positivo disto é que a circulação do livro chegou com agilidade até os leitores jovens, propiciando-Ihes o contato diversificado e atualizado com o repertório editorial que se difundiu nas últimas décadas no país. Por outro lado, gerou interesses e estratégias que não se livram da massificação tanto dos produtos ofertados quanto dos leitores; há mecanismos mercantilistas que se impõem, atendendo supostas necessidades (ou gerando-as também), ditando indicações de consumo, forçando ofertas e aqui entra um ponto de interferência na liberdade/ espontaneidade artística, proveniente de critérios como: pesquisas no mercado sondam o que é mais vendável e rentável, e publicações em torno de um mesmo assunto ou situações possivelmente lucrativas criam redundância de conteúdos, entre outros fatores massificantes.

Nessa contextura, a recepção pode ser condicionada por diferentes apelos, respondendo a motivações de significado subjetivo, que brotam da liberdade de escolha (o que afeta os leitores mas também os autores), pode pressupor leituras que criem relações entre leitores, onde as descobertas sejam compartilhadas com afeto, onde haja trocas emocionais, intercâmbios, soma de idéias, questionamentos, diversidade de 
opiniões, colocando-se, nesta rede: professores e alunos, alunos entre si, alunos e suas famílias e comunidade; bibliotecário escolar e usuários. E ainda responder a manipulação externa, que se exerce contra: opções pessoais (não só do leitor infantil e juvenil, mas dos próprios promotores de leitura); o prazer da sintonização profunda; a relação do leitor com a obra por impulso espontâneo e curioso, entre outros fatores, sem os quais é impossível um significado autêntico, gerador de acréscimos ao modo de ver, pensar, criar, sentir.

Muitos outros pontos envolvem o questionamento do tema a literatura infantil e juvenil em foco - o ensino, a pesquisa e a publicação. As instituições sociais, políticas, pedagógicas e a estrutura econômica têm o poder de favorecer ou inibir o acesso a publicações que circulam no mercado? Que heranças culturais compõem o perfil cultural do Brasil, de histórico colonialista, em especial as referentes às leituras literárias? Em que medida a cultura de massa e os novos meios digitais e de comunicação incorporam a cultura do livro e da leitura e contribuem para a assimilação de produtos culturais mais duradouros, ou, ao contrário, enfraquecem a capacidade receptiva dos espectadores, interferindo no seu convívio com o texto literário escrito?

Tendo em vista a escola brasileira, o que tem sido pesquisado, aplicado e reformulado com eficiência no plano de alfabetização/ letramento? Qual a filosofia de educação e as bases estéticas que fundamentam, nas escolas, os seus programas de leitura literária (caso Ihes seja dedicado espaço no planejamento global)? Será que as bases que têm prevalecido na escola, como um dos canais de transmissão da cultura literária, estão de acordo com o campo de Humanidades a que pertence a Literatura? Que providências estruturais, reformas curriculares, iniciativas teórico-reflexivas e metodológicas permeiam o ensino em todos os níveis, e principalmente o de graduação e pós-graduação, preocupado em se acertar melhor em vista dos reflexos nos níveis que o precedem, atento a enfrentar contradições, conflitos e superar desacertos?

Muitas são as questões relacionadas ao tema que inquietam aqueles que têm ou terão a sua formação na área de Letras. Talvez a mais perturbadora seja esta: como assumir a promoção da leitura com sucesso, traduzido em transformações palpáveis na vida do indivíduo e da sociedade brasileira? Este sucesso será medido pelo grau de maturidade da consciência: politizada, ávida por conhecer sempre mais, desejosa de mudanças para o mundo, sendo capaz de contribuir para torná-las reais. A condição crítica atingida pelo leitor, cuja formação se inicie na escola, revela-se na sua capacidade de ir além dela, elevando as exigências, os interesses e os repertórios, com proporções culturais. Neste nível, forjam-se identidades fortalecidas, livres do risco de se "dissolverem no ar", ou serem tragadas por uma realidade desagregadora de valores essenciais. 
Ainda que os leitores tenham atingido estágios de leitura independente, a sua maturidade não é exercida por fórmulas que isolem atitudes cognitivas da sensibilidade e da imaginação, ou estranhas ao admirar ou não admirar, se emocionar, se envolver com mais intensidade ou menos, devido a maior identificação com a obra ou não. É certo que, na passagem evolutiva de estágios de leitura, as necessidades subjetivas superam a disposição lúdica do brincar pelo brincar e direcionam-se para novos motivos e questionamentos de ordem existencial e social. Ao longo dos estágios, o leitor define afinidades e preferências de visão, abordagens e estilos literários.

Tanto em leituras literárias de fruição gratuita, isenta de esforço mental interpretativo, como em explorações analíticas de penetração racional-reflexiva mais funda, a leitura se realiza pela motivação receptiva ao "comer", ação pessoal que não tem como o outro realizar por mim com proveito; não tem sabor na boca alheia o que eu mastigo e transporto para lá, para que engula passivamente, ou se limite à articulação mecânica de letras, sons, sintagmas, sem que o corpo, no seu todo, internalize o que lê, predisposto à elaboração visceral (física, cognitiva, afetiva). $\mathrm{O}$ ato de nutrir-se com o livro presume faltas subjetivas a serem preenchidas, "fome" e "sentir o gosto". No conceito do livro "comestível" de Lobato, em A reforma da natureza, está inerente a idéia simbólica da mastigação-degustação com prazer. Emília a expõe na interlocução com a rãzinha:

- Muito simples. Em vez de impressos em papel de madeira, que só é comestível para o caruncho, eu farei os livros impressos em um papel fabricado de trigo e muito bem temperado. A tinta será estudada pelos químicos - uma tinta que não faça mal para o estômago. O leitor vai lendo o livro e comendo as folhas; lê uma, rasga-a e come. Quando chega ao fim da leitura, está almoçado ou jantado.

Que tal? [...]

Dizem que o livro é o pão do espírito. Por que não ser também pão do corpo? As vantagens seriam imensas. Poderiam ser vendidos nas padarias e confeitarias, ou entregues de manhã pelas carrocinhas, juntamente com o pão e o leite. (LOBATO, 3 b, 1973, p. 104).

Roland Barthes admite que "o saber-ler pode ser delimitado, verificado no seu estágio inaugural, mas bem depressa se torna sem fundo, sem regras, sem graus e sem termo" (BARTHES, 1988, p. 45). Parece-nos que a inviabilidade da "pertinência"² e a perversão sempre da estrutura, alegada por Barthes, se justificam pelas infinitas variáveis e variações do desejo, imprevisível e gerador de influências no espaço subjetivo (onde ele

\footnotetext{
${ }^{2}$ Em $O$ rumor da língua, capítulo "Da ciência à literatura", Roland Barthes faz referência à "pertinência”, sob o prisma da lingüística: "o ponto de vista sob o qual se escolhe olhar, interrogar, analisar um conjunto tão heteróclito, díspar, quanto a linguagem.” (p. 44). Suas discussões permitem pensar, inclusive, que a conotação confere à leitura o infinito, e, sob este prisma, "não há injunção estrutural para fechar a leitura." Assim, é possível lançar ao texto a definição da im-pertinência, admitindo que nele permanece algo de ilegível, por mais legível que ele tenha sido concebido.
} 
é produzido) e nas relações leitor-texto que sofrem os seus efeitos. As considerações do crítico são compatíveis com a leitura literária e as conotações da literatura, e nos impelem a afirmar que a conotação operacional preside as duplicidades artísticas e urde as vertentes simbólicas (solo das emoções, da fantasia, da intuição), onde os desejos repercutem, afloram, são alimentados ou se frustram.

É porque toda leitura é penetrada de Desejo (ou de Repulsa) que a Anagnosologia [traduzimos por estrutura-síntese, padrão generalizante] é difícil, talvez impossível - em todo caso, que ela tem possibilidade de efetuar-se onde não a esperamos, ou pelo menos não exatamente onde a esperamos: por tradição recente - nós a esperamos do lado da estrutura; e sem dúvida temos, em parte, razão: toda leitura passa pelo interior de uma estrutura (mesmo que múltipla, aberta) e não no espaço pretensamente livre de uma pretensa espontaneidade: não há leitura "natural", "selvagem": a leitura não extravasa da estrutura; fica-Ihe submissa; precisa dela, respeita-a; mas perverte-a. A leitura seria o gesto do corpo (é com o corpo, certamente, que se lê) que, com um mesmo movimento, coloca e perverte a sua ordem: um suplemento interior de perversão. (BARTHES, 1988, p. 45).

O Desejo e a Repulsa, fundamentando a impertinência, são irmãos gêmeos da liberdade, porque ninguém obriga ninguém a desejar ou não, nem há como transpor para alguém o meu desejo (ou vice-versa), ou depositá-lo mecanicamente no interior do outro frente ao texto; eles são impulsos processados internamente, e, não raro, por razões inconscientes; têm justificativas íntimas. A quem intermedeia a leitura literária é possível despertar curiosidade, vontade, ânimo, motivação, interesse alheios; ao contagiar outrem, no intuito de compartir significações, pode até conseguir provocar, se não em todos, em alguns, diferentes ressonâncias interiores, com desejos aflorados, alimentados ou não.

Desejo e prazer se complementam e têm larga significação. O prazer, não limitado à satisfação fácil e leve, assimila sentimentos de dor, sofrimento, tensões, tristeza, decepção, medo, angústia, e outros que não são tradução de alegria, mas brotam das paixões que povoam o mundo ficcional da literatura e comandam a alma humana. Então, o prazer na leitura não se resume em experimentar riso, humor, alegria, alívio, provenientes de solução de tensões, efeitos satisfatórios à expectativa convencional, retomada da normalidade pela volta ao equilíbrio externo da história, final feliz, etc.

A literatura infantil identificável pelo patamar da linguagem literária - não aquela que se reduz a diversão instantânea e superficial, passatempo - não descarta a realidade vivencial imersa em paixões básicas, que perfazem a experiência de vida e morte. A criança é perfeitamente apta a mergulhar e deixar-se inundar por sentimentos, porque, como todo ser humano de qualquer idade, ela conhece alegrias e tristezas, ódio e amor, experimentando existencialmente as mesmas condições metafísicas. A literatura de 
qualidade estética, seja ela adulta, infantil ou juvenil, enreda questões dessa natureza, veladas pela fantasia; com revestimentos próprios do imaginário, os reais que ela urde não têm parâmetro de constatação óbvia, não se definem como retratação documental tendente a fidelidade histórica, não põem o leitor frente ao espelho do lugar comum, precário, de reconhecimento explícito, do qual talvez ele já faça parte ou seja expectador.

\section{Conclusão}

A leitura de um modo geral e a literária, em especial, interferem na consolidação de valores, no condicionamento de modos de vida e de mentalidades, influindo na consolidação ou rarefação identitária dos indivíduos e da sociedade. Tendo em vista as práticas da leitura literária fundamentadas em orientações humanizadoras, não submetidas a um didatismo alienante, contribuem com a formação da consciência crítica e o refinamento da sensibilidade, que se refletem nas relações humanas, na evolução social e na ordem histórica vigente e por vir. Certamente, o mediador de leitura e possível formador de leitores que se ausenta, quando deveria estar entre e com estes leitores e a obra literária, está incapacitado para atuar com a literatura, como campo rico e aberto da área de humanidades, por não gostar de ler, por equivocar-se nos meios e levar a fins anti-estéticos, anti-educativos. Por isto mesmo, investimentos no âmbito do ensino e da pesquisa podem fomentar: o contato mais vital e enriquecedor com publicações não só de obras para crianças e jovens, inclusive traduzidas e reeditadas, mas com o acervo que se vem constituindo sobre história da leitura e do livro; a discussão da democratização do acesso e da efetivação de políticas escolares; a promoção da leitura através da experimentação de projetos de leitura bem estruturados e eficazes; a crítica literária e a formação crítica do leitor; o conhecimento da história nacional do livro, da leitura, de leitores, etc.

Ao se debruçarem sobre questões reflexivas, teóricas e práticas, o ensino, a pesquisa e a crítica, em interação, têm propriedade e competência para promover o nível de autonomia do pensamento, para que os sujeitos, individualmente e na convivência social, pensem e criem com liberdade, o que legitima o poder para sonhar, transformar-se e transformar os espaços externos. Volta à escola (a Universidade interligada aos outros níveis de ensino) a possibilidade de inserção na realidade imediata, enfrentando conflitos vigentes entre o pedagógico e o estético, escolarização e literatura, leitura ingênua e leitura crítica; ela pode intervir e reformular, ao experimentar, teorizar, propor concepções e metodologias coerentes com a complexidade humana e os saberes, inclusive os humanísticos, de modo que o acesso a bens culturais e à leitura literária repercuta no movimento renovador de mentalidades, no enriquecimento do conhecimento e da cultura. 
Não só degustada pela criança, mas mesmo ocupando o lugar de estudo até na Universidade, a Literatura Infantil pode ser vista sob o olhar do prazer, que faz aflorar emoções, memórias, sonhos. O prazer não é incompatível com a crítica alicerçada em conhecimentos iluminadores da natureza intrínseca do objeto "literatura" e de leituras que estabelecem liames sutis com o plano externo, histórico-social, cultural. Livros infantis resultantes das multilinguagens têm grande potencial interpretativo, e a sua leitura se abre à complexidade do pensamento, ao aprofundamento de dimensões interiores, às associações também objetivas, às projeções multidisciplinares.

Reiteramos, no desenvolvimento do tema, que a Literatura Infantil tem no seu bojo obras de riqueza estética formidável, cujos modos de produção estão centrados na interrelação de linguagens várias, inclusive de arte. Sendo assim, não se lê, em tais obras, só e isoladamente a palavra, mas o livro enquanto objeto inter-semiótico, onde se integram: signos verbais, visuais, gráficos, espaciais; neste caso, a materialização gráfico-visual das letras, das palavras, dos segmentos frasais, dos parágrafos, na forma do texto, enfim, agrega sentidos semânticos. A educação que familiariza o leitor com as multi-formas, com a simultaneidade dos modos de produção gráfica e literária, renova-lhe o repertório de leituras (lingüísticas, artísticas, culturais, etc.). Admitindo que os dispositivos da escrita se ampliam no século $X X$, desagregando modelos de percepção linear, validamos a visão multirelacional para a recepção do livro infantil, e pomos em cheque separatismos entre conteudismo e formalismo, colocando-nos, como Roger Chartier,

Contra a definição puramente semântica do texto - na qual residem não apenas a crítica estruturalista, em todas as suas variantes, mas também as teorias literárias mais cuidadosas em reconstruir a recepção das obras - é preciso levar em conta que as formas produzem sentidos e que um texto, estável por extenso, passa a investir-se de uma significação e de um status inéditos, tão logo se modifiquem os dispositivos que convidam à sua interpretação. (CHARTIER, 1994, p. 13).

As nossas palavras finais, endossando a teoria de Luigi Pareyson, reforçam a necessidade de a leitura ter fundamentos estéticos, pautada em direções não compartimentadas do olhar, o que se aplica fundamentalmente ao "livro infantil", fruto de inovações modernas. $O$ esteta alerta para a minudência de significações na arte, o que nos confirma a riqueza da fusão de linguagens no livro para crianças, objeto novo, de faces físico-espacial, gráfico-verbo-visual, tátil- plástica em simbiose:

Aquele objeto físico e sensível que é a obra de arte foi formado por uma série de gestos que eram esta mesma sensibilidade toda tornada modo de formar, e, por isso, agora a contém, denuncia, declara, revela, exprime. Nesta perspectiva, portanto, se a forma é uma matéria formada, o conteúdo não é outra coisa senão o modo de formar aquela matéria. 
$[\ldots]$

É preciso não esquecer que na arte o conteúdo entra, precisamente, sob forma de arte, isto é, arrastado pelo gesto formativo do artista. Dito isto, é preciso logo acrescentar que, justamente por isso, qualquer coisa, em arte, está prenhe de conteúdo, carregada de significado, densa de espiritualidade, embebida de atividades, aspirações, idéias e convicções humanas. Precisamente porque o artista resolveu toda vontade expressiva, significativa no fazer, no gesto formativo, na atividade operativa, precisamente por isso tudo, em arte, até a coisa aparentemente mais irrelevante diz, significa, comunica alguma coisa. (PAREYSON, 1997, pp. 62-3 e 68, respectivamente).

\section{Bibliografia}

BARTHES, Roland. O rumor da língua. Trad. de Mário Laranjeira. São Paulo, Brasiliense, 1988.

CHARTIER, Roger. A ordem dos livros - leitores, autores e bibliotecas na Europa entre os séculos XIV e XVIII. Tradução de Mary Del Priore. Brasília, Editora da Universidade de Brasília, 1994.

Jornal do Professor de 1ํgrau. Brasília, oㅜ 5, publicação do MEC/ INEP, março, 1987. LOBATO, Monteiro. A barca de Gleyre. 14. ed. São Paulo, Brasiliense, 1972. Obras Completas de Monteiro Lobato. $1^{\underline{a}}$ série. Literatura geral. Vol. 8.

A reforma da natureza. São Paulo, Brasiliense, 1973. Obras Completas,

Série b, Vol. 3 .

Memórias da Emília. São Paulo, Brasiliense, 1973. Obras Completas,

Série a, Vol. 2.

MIRA, Maria Celeste (coordenação de pesquisa e texto). Momentos do livro no Brasil. São Paulo, Ática, 1996.

MORIN, Edgar. A cabeça bem feita - repensar a reforma reformar o pensamento. Trad. de Eloá Jacobina. 5. ed., Rio de Janeiro, Bertrand Brasil, 2001.

PAREYSON, Luigi. Os problemas da estética. Trad. de Maria Helena Nery Garcez. São Paulo, Martins Fontes, 1997.

RESENDE, Vânia Maria. "Ziraldo e o livro para crianças e jovens no Brasil - revelações poéticas sob o signo de Flicts e reflexos prismáticos em obras de autores de língua portuguesa". Tese apresentada à área de Estudos Comparados de Literaturas de Língua Portuguesa da USP, defesa em 14 de setembro de 2004.

SOARES, Magda. Capítulo "A escolarização da literatura infantil e juvenil". In:

EVANGELISTA, Aracy Alves Martins et al (org.). A escolarização da leitura literária. Belo Horizonte, Autêntica, 1999.

TURCHI, Maria Zaira. Capítulo "Espaços da crítica da literatura infantil e juvenil". In:

TURCHI, Maria Zaira et SILVA, Vera Maria Tietzmann (organização). Leitor formado, 
leitor em formação: a leitura literária em questão. São Paulo, Cultura Acadêmica; Assis, ANEP, 2006. 